\title{
Value Stream Mapping as a tool for the optimization of production - case study
}

\author{
Jolanta B. Krolczyk ${ }^{1, *}$, Stanislaw Legutko ${ }^{2}$, and Anna Szczepańska ${ }^{2}$ \\ ${ }^{1}$ Opole University of Technology, Faculty of Mechanical Engineering, 76 Proszkowska Street, 45-758 \\ Opole, Poland \\ ${ }^{2}$ Poznan University of Technology, Faculty of Mechanical Engineering and Management, 3 Piotrowo \\ Street, 60-965 Poznan, Poland
}

\begin{abstract}
The aim of the paper is to present the possibility of introducing improvements in processes concerning production logistics basing on the use of value stream mapping. An analysis of the current situation in order to identify waste and problems in the stream flow has been carried out. Subsequently, a future shape map has been drafted with a proposal concerning the manner in which future state ought to be achieved. The thesis is concluded with a general summary as well as conclusions regarding the studied subject and the proposals for further work.
\end{abstract}

\section{Introduction}

Material flow and Value Stream Mapping (VSM) has been recognized for its effectiveness in improving productivity [1], product quality [2-4] and on-time delivery. Many manufacturers try to collect information connected with product quality such as defect rates [5-7] or error rates [8]. VSM is a method which is applied to the analysis of the production system. It is also a tool which gives the opportunities to the improvement of the material and information flow processes' consistency in the Lean Manufacturing. This tool helps to understand the flow of information and materials during the route which is spend by the product in the stream of values. One should trace the production route of the product from the customer to the supplier, with the accurate graphical representation of the each of processes participating in the material and information flow. The mapping can be successfully transferred into the all divisions and areas, from the production sphere to administrative and office processes. The common feature of the all business processes is a time, which elapses from the instant of initiation process to the finish. The waste in the business process manifests always in a form of an excessively long time. The time reduction is a primary objective of the advancement, according to the Lean Management, independently on the discussed area, e.g. production, administration, service or health service. Mapping allows to clearly illustrate the ineffectiveness of action, measures the

\footnotetext{
* Corresponding author: j.krolczyk@po.opole.pl
} 
waste level and supports to design the appropriate changes, independently on economic activity's character [9].

The aim of the paper is to present the possibility of introducing improvements in processes concerning production logistics of aircraft parts basing on the use of value stream mapping.

\section{Stages of Value Stream Mapping}

Value stream mapping allows the identification of activities which constitute the waste. The wastes in the production can be found in the easiest way after the total presentation of process flow in the graphical form and indication of material and information flow in the process. After the map development, it is easy to identify the locations in which the materials, semi-finished products or final products are halted in the particular place for the longer time, instead of flowing to the customer [10]. In the value stream mapping, the specified graphical symbols are being applied, which enables the clear and transparent process presentation, as well as the identification of places intended to the advancement.

Value stream mapping consists of a few following stages [11]:

1) The selection of products' family. The family of products can be defined as products, which pass through the same working places and technological operations, however it is unnecessary to pass any type of product through the all working places.

2) The selection of mapping stream manager. His task is maintenance of the value stream flow and reaction to the appearing problems. Manager should have responsibilities and rights for making decisions correlated with the work of the all organizational cells affected by the flow of the particular products' stream.

3) Acquiring the information about the process. In order to create the map of the current state, one should cross the route, which is physically passed by the products „from door to door", measure how many time they spend on the particular working places, where and how long they await for the next operation and how they get to the client. The following information are primarily gathered: suppliers' requirements regarding the ordered batch size, the type of products or the method of supply; requirements of our company concerning the deadline of orders by customers; requirements of our suppliers to order materials for the production of the analyzed product family; types of manufacturing operations; durations of operations; changeover times; availability of jobs; shift-work organization; the number of operators of machines and equipment used in the process; way of production planning and allocation of production tasks; planning shipments to the customer, inventories of materials, products in the production and finished products; ways of communication process between the customer and our organization, the organization and the supplier, the division of production planning and production departments.

4) Development of maps of the current state. Graphical presentation of the activities using specific symbols.

5) Analysis of maps: the search for losses, identification of problems, proposing solutions.

6) Development of a future state map. Graphical presentation of proposals for the elimination of waste.

7) Development of a plan for implementation of the future state. Proposing changes according to a fixed plan with specific objectives, tasks, deadlines and responsibilities.

8) Implementation.

9) Evaluation of the results. 


\section{The specification of the selected production process}

The analyzed manufacturing company employs 1200 employees who work in 10 locations around the world. Branch in Poland, specializes in precision machining of difficult-to-cut components of aircraft engines, and currently employs approx. 130 employees. The company is working on 3 shifts. Main products are turbine steering parts - for the aerospace and turbine blades - for the energy industry. Typical types of manufactured parts are shown in Fig. 1.
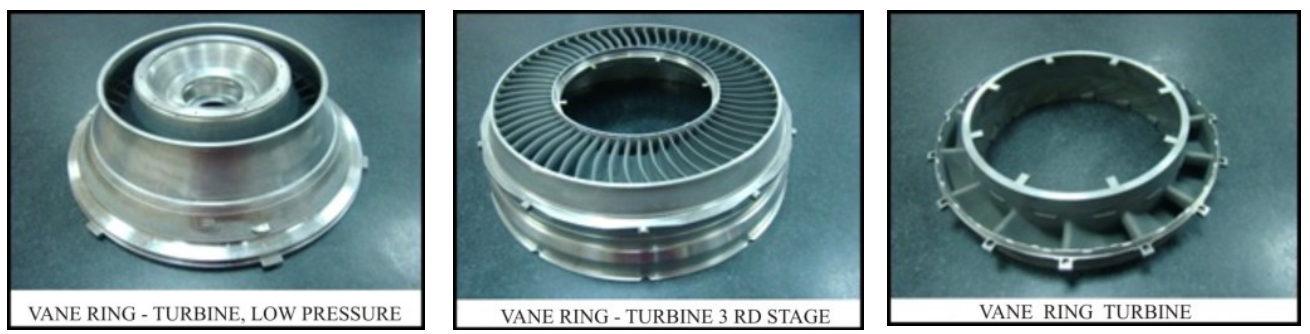

Fig. 1. Typical types of manufactured parts.

The selected optimization process is the production process of the "Turbine Control Apparatus" (Fig. 1 middle). Parts of this type are included in the aircraft engine. This part is responsible for directing the combustion exhaust gases. These are the non-rotational, complex-shaped components in the engine. The starting material for producing these parts is the precise mold made of aircraft material with high nickel content. According to the literature [12-14], the machining of parts with complex shapes requires the selection of the appropriate cutting conditions enabling the reduction of forces and vibrations occurring during the machining process. Structurally this part consists of two outer and inner rings which are connected by vanes. This part is being manufactured in different configurations. The company produces 32 types of this part. Each part is produced in a different monthly amount, according to customer demand for a specific type and class. The annual production is in the range of 9000 parts. Due to the similarity of all parts, the technology can be divided into families and thus it has been formed:

- Family I - parts machined roughly and in finishing conditions with heat treatment.

- Family II - parts machined roughly and in finishing conditions with hard brazing of honeycomb type rings.

- Family III - parts machined roughly and in finishing conditions with a plasma protective coating imposed on selected surfaces.

- Family IV - parts machined rough and in finishing conditions and additional assembly (riveting of lids on the inner ring).

All mechanical processes and assembly (riveting) are performed on the spot in the company. Special processes such as heat treating, brazing and plasma coating of protective layers are performed in cooperation approved by the customer source. In an article the optimization of the selected part of the family I is presented. The Family I consist of 6 part numbers and represents approximately $25 \%$ of the company's production. Because of the very great technological similarity of the parts from the family I, it was assumed that the parts can be described in one standard technological process (Fig. 2), which is shown below:

$\checkmark$ Turning - preparation the bases of machining,

$\checkmark$ Turning II - roughing,

$\checkmark$ Turning III - roughing,

$\checkmark$ Grinding I - roughing,

$\checkmark$ Bench work roughing, 
$\checkmark$ Cooperation - heat treatment,

$\checkmark$ Grinding II - improvement of the bases after heat treatment,

$\checkmark$ Turning IV - finishing,

$\checkmark$ Grinding III - finishing,

$\checkmark$ Grinding IV - finishing,

$\checkmark$ EDM sink, WEDM, milling - finishing,

$\checkmark$ Bench work finishing,

$\checkmark$ Control FPI, flow control, control CMM.

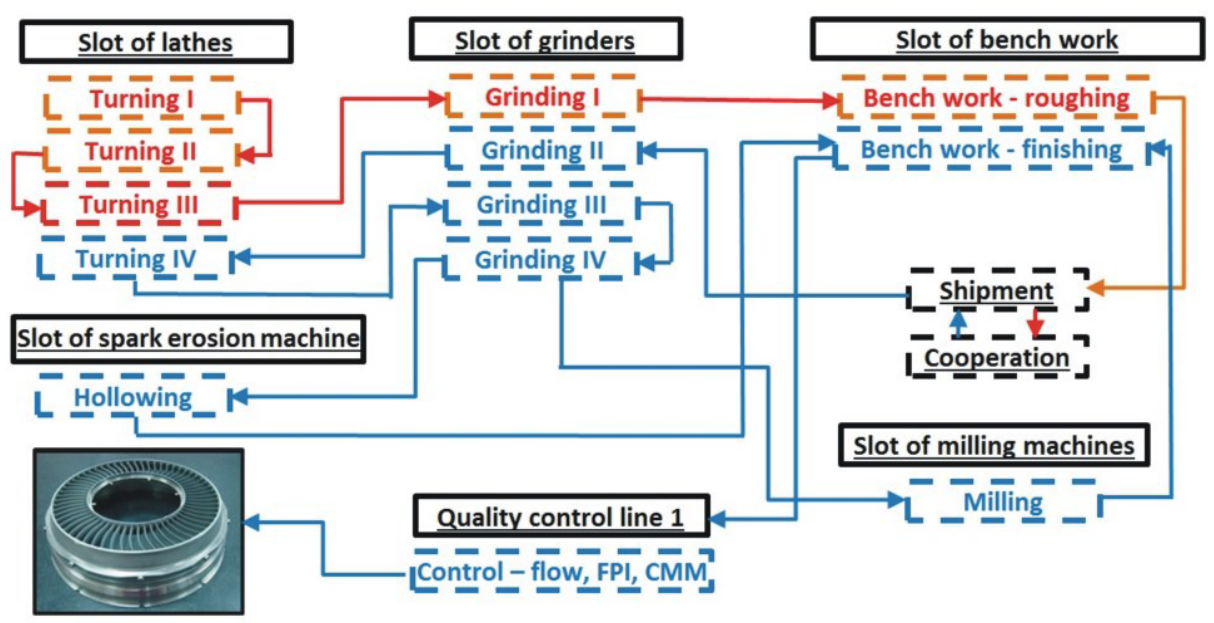

Fig. 2. Graphical representation of the technological process for the Family I.

Due to the similarity of parts from the family I, one can adopt the following assumption for the analysis needs, and treat the part of the family as one part representing $25 \%$ of total production in quantities of 2356 units/year which gives 196 units/month and 50 units a week. The production process ends with the transfer of part to a warehouse for finished products. Parts are sent to the customer normally once a week on Tuesday. In exceptional cases, parts can be shipped on Friday as additional shipping. In the analysis of the current situation, only process of the part flow through the production unit was taken into account. It did not take into account the technological process, i.e. the technical details of manufacturing. The analysis starts with determining: what is the cycle time for the selected part of the family. Calculation of the cycle time begins from the determination of the time available per one change in the production company which is 465 minutes ( 8 hours decreased by the breakfast break - that is 15 minutes). The standard unit of time to determine the tact time is a second. However in this work, due to the long cycle times and long operation times of changeovers, the unit of a minute has been applied. Then, one should divide the obtained value by the customer's requirements, which are equaled to 3 parts, based on the change in production. Subsequently, the value of tact time of 155 minutes is obtained. The resulting cycle time means that to meet customer demands within the available time, the company should exempt the customer "Turbine Control Apparatus" every 155 minutes. The resulting value does not include the time of machine failures, the times required for retooling and lost time for the production of poor quality products, popularly called deficiencies. These wastes are things that a company must deal with, because they reduce the time available for production. Another element of map for the analysis is the technological process, used resources, work stations (machines) and their arrangement on the manufacturing floor. Browsing the technological route, it can be seen that the process is divided into three main stages: 
$\checkmark \quad$ rough treatment - includes: turning I, II, turning, turning III, IV turning, grinding and rough bench works,

$\checkmark \quad$ The heat treatment - carried out in cooperation,

$\checkmark \quad$ Finishing treatment - includes: grinding II, V, turning, grinding III, V, grinding, milling, bench work in finishing conditions and control.

In contrast, the current layout for machines on the manufacturing system is a nest. In this system, we have such a slot:

$\checkmark \quad$ Lathes -9 fully convertible machines in a 3 slot system per 3 machines,

$\checkmark \quad$ Grinders - 9 machines in a 1 × 3 machines plus 3 slot per 2 machines,

$\checkmark$ EDMs - 6 machines in a 3 slot system per 2 machines,

$\checkmark \quad$ Milling machines - 2 machines in a 1 slot system, 2 machines,

$\checkmark$ Bench work -3 stands in one slot.

Fig. 3 shows the map of the current state of the production process.

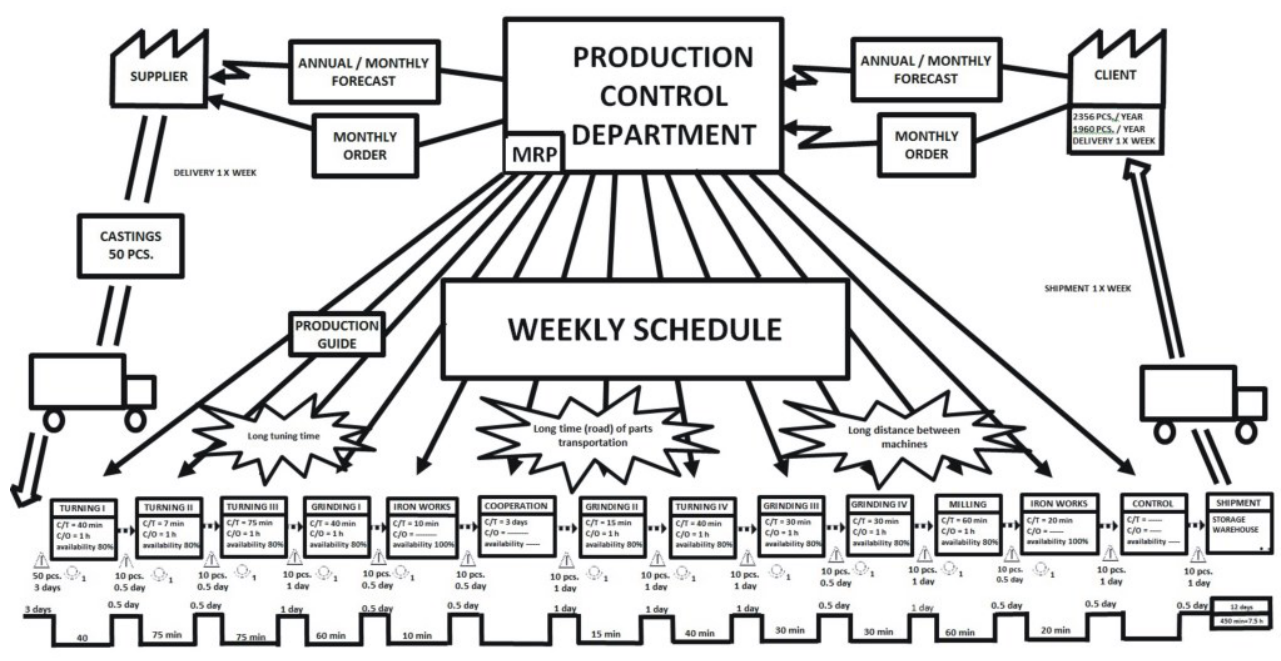

Fig. 3. The map of the current state

The analysis of the current situation maps and the collected information allowed the identification of value streams, i.e. all activities, both adding and not adding the values. Summing up the analysis of current state, the following elements have been specified to improve:

$\checkmark$ Reduction of failure and increase the availability of machines,

$\checkmark$ Shorter setup times,

$\checkmark$ Reorganization of the machine settings,

$\checkmark$ The establishment of the zone dedicated to roughing and finishing,

$\checkmark$ Introduction of the FIFO method for all machines where possible.

\section{Optimization of production - the development of the future state map}

All parts manufactured in the company are grouped in families according to the similarity technology, which also shows that for every part the division to the aforementioned stages (roughing, finishing and cooperation) occurs. Therefore, a certain conclusion can be formulated. In order to improve the flow of parts through the production department, one should distinguish the two production zones, namely: roughing and finishing (Fig. 4). 
Between them an additional area for shipping parts to the cooperation can be created. According to this assumption, the time associated with the transport of parts between operations should be reduced, which at large distances between the machines and high frequency, should give tangible effect of shortening the time wasted on these activities.

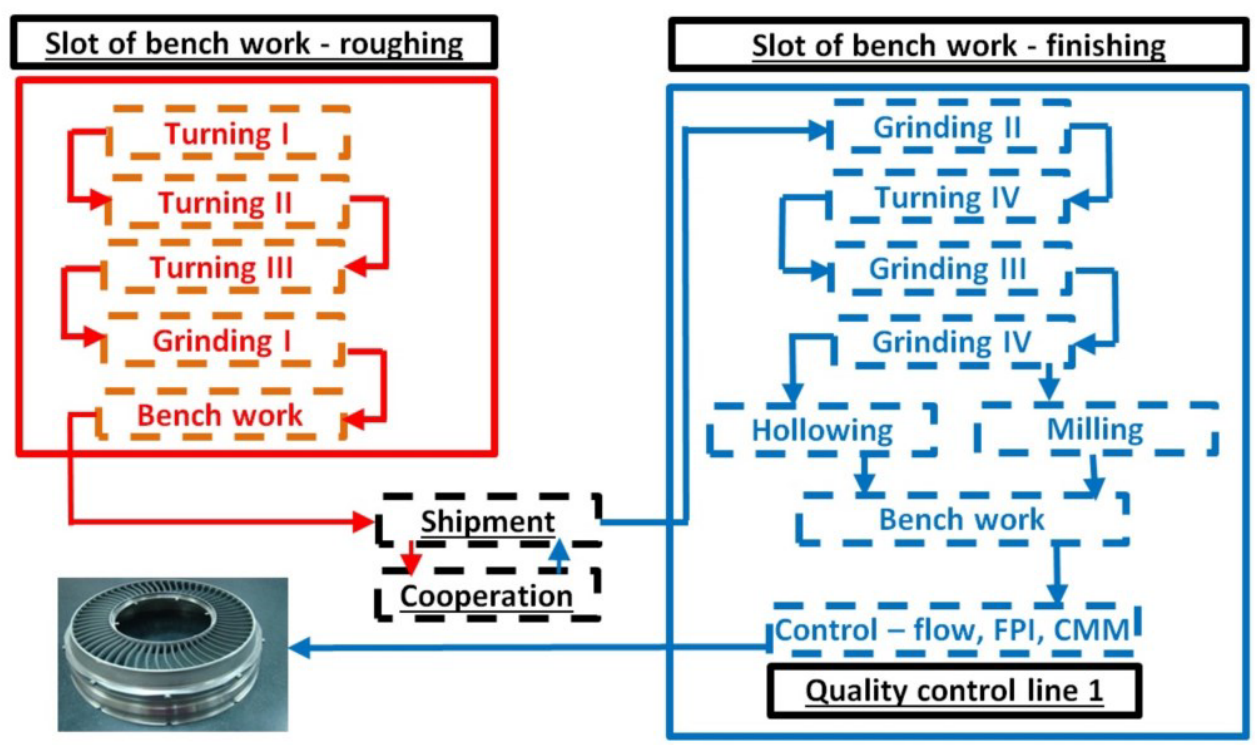

Fig. 4. Future state - graphical presentation of the technological process for the Family 1

The reduction of machine downtime and high availability of machine time can be achieved through a well-executed assumptions of TPM (Total Productive Maintenance). TPM goals are realized in two areas: human and machine. In the first area, the task of TPM is to increase the efficiency of employees by expanding their skills and knowledge - which is synonymous with an increase in their responsibilities. From the perspective of machine, operation workers should focus on the maintenance of machinery and equipment in a state of high availability in such a way that the maintenance department will receive from the operators the information regarding the state of the whole machine park, in order to plan actions. Maintenance services move from reaction to the predictive maintenance of machines (analyzing the occurring defects to predict what might happen in the future), thus increasing machine availability, and reliability. To shorten setup times, the SMED methodology is applicable [15]. According to this methodology, the information regarding retooling for operations on the parts from the family I, as well as for roughing and finishing have been collected. Tooling hire place is located at a distance from the particular machines therefore the transport of holders takes the longest time. It can be assumed that it is on average about $60 \%$ of the total changeover time. It will not be possible to eliminate this time completely, but it is possible to significantly shorten its value. The solution proposal is to put the necessary handles on the shelves within the close distance to the machine tools in the field of crane located above them. Optimization per month, only for a part from the family I, gives 81 extra hours to produce. One of the general principles of lean manufacturing is the introduction of continuous flow wherever possible. Continuous flow is a term referring to the production of one part transmitted between neighboring operations without downtime and waiting and thus without the generation of other types of waste. In the presented case, the introduction of continuous flow is not possible because the heat treatment is carried out at the external provider. The solution in this case may be the use of so-called FIFO queue, i.e. the type of queue: "first in, first out". The establishment of such a 
FIFO queue in front of the machine can order the parts and operations in terms of the sequence of their execution and do not require the creation of a daily or shift production schedule for individual machines. The actions implementing the FIFO principle will require the least procedures. These will include the selection of places by the machines on a newly designed machines' setting plan. Already at the design stage of a new set of machines, the introduction of a FIFO queue should be taken into account. According to the future state map (Fig. 5) FIFO should be included on all machines intended for roughing and finishing. Queues should be marked on the floor as squares forming a trolley's projection with a suitable FIFO designation.

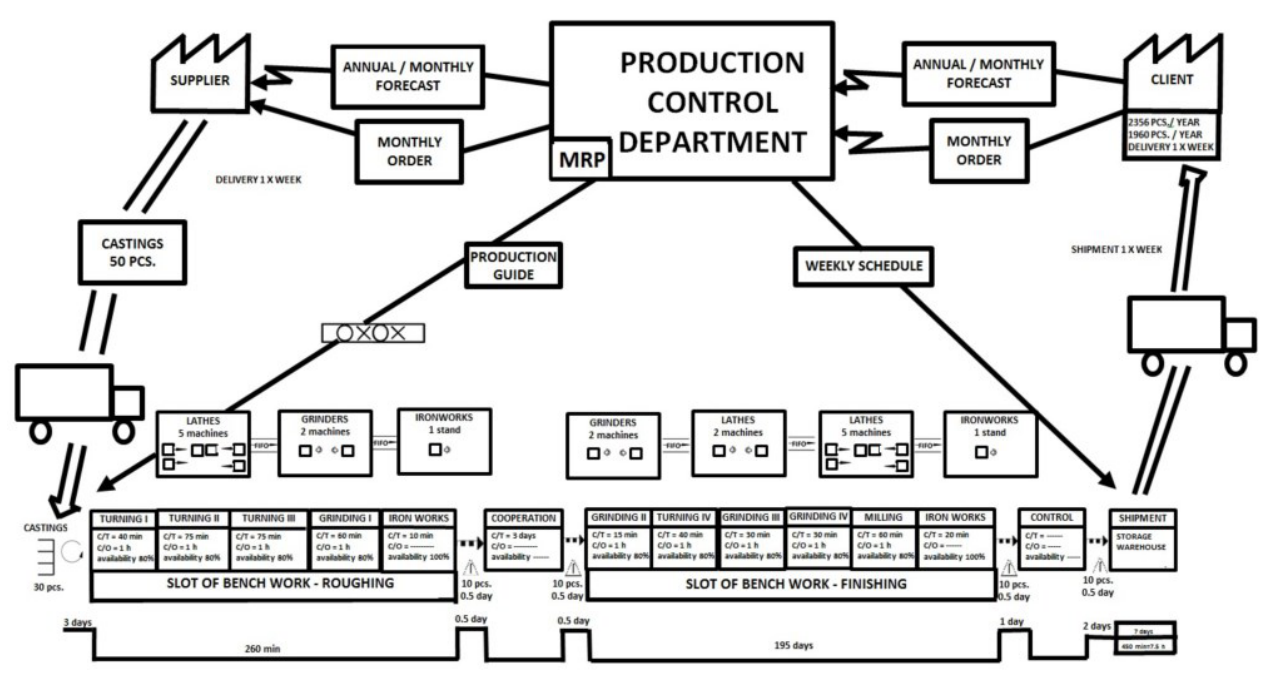

Fig. 5. Future State Map

\section{Conclusions}

1. Value stream mapping is a method by which one can get closer to achieving continuous flow from the beginning to the end of the stream values in the company. The consequence of actions and their implementation in order to achieve a future state becomes a very important element. Multiple mapping of the same value stream can discover another source of waste to eliminate. Therefore, a continuous improvement of the stream value that can be successfully accomplished by utilizing the method of Value Stream Mapping and Lean Manufacturing tools is essential.

2. Value Stream Mapping has helped to achieve this goal by limiting the production cycle from 12 days to 7 days. It should be noted that 5 days should be add to this time in order to complete the co-operation (which is not shown on the map, and is governed by a trade agreement between the company and cooperator).

3. The elimination of the identified waste is proposed to implement with the available tools of Lean Manufacturing. The main improvements are: shorter setup times, reducing downtime and increasing machine availability, reorganization of the settings of the machine, creating a zone for roughing and finishing, the introduction of the FIFO principle for all machines.

4. Achieving a future state for the selected group of the parts from the family 1 , according to the Map of Future State should not complete the improvements throughout the whole stream value. Further work should focus on the execution of the same activities for families 
in the field of II - IV. During the improvement of machines' settings for the Family I and the organization of roughing and finishing sockets, all parts manufactured in the company were taken into account. The calculations for the amount of the necessary machines in the slots were made for the entire production.

5. The result of each subsequent mapping should include the saved activities to be performed in order to achieve the future state. According to the lean philosophy, one should not try to solve all the problems at one time. The quest for the perfect flow by making small steps can give a more tangible effect than a creation of a comprehensive schedule that will be difficult to implement.

\section{References}

1. J.B. Krolczyk, G.M. Krolczyk, S. Legutko, J. Napiorkowski, S. Hloch, J. Foltys, E. Tama, Teh. Vjesn., 22 (6), 1447-1456 (2015)

2. S. Wojciechowski, P. Twardowski, M. Pelic, P.W. Maruda, S. Barrans, S., G.M. Krolczyk, Precis. Eng., 46, 158-165 (2016)

3. D. Lehocka, J. Klich, J. Foldyna, S. Hloch, J.B. Krolczyk, J. Carach, G.M. Krolczyk, Measurement, 82, 375-383 (2016)

4. A. Glowacz, Meas. Sci. Rev., 15, 167-75 (2015)

5. C. Zhang, Z. Li, C. Hu, S. Chen, J. Wang, X. Zhang, Meas. Sci. Technol., 28, 35102 (2017)

6. J.B. Krolczyk, B. Gapinski, G.M. Krolczyk, I. Samardzic, R.W. Maruda, K. Soucek, S. Legutko, P. Nieslony, Y. Javadi, L. Stas, Teh. Vjesn., 23 (1), 301-306 (2016)

7. P. Hreha, A. Radvanska, L. Knapcikova, G. M. Królczyk, S. Legutko, J.B. Królczyk, S. Hloch, P. Monka, Metrol. Meas. Syst., 22 (2), 315-326 (2015)

8. J.V. Saraph, P.G. Benson, R.G. Schroeder. Decision sciences, 20 (4), 810-829 (1989)

9. M. Rother, J. Shook, Naucz się widzieć (LEI Polska, 2009)

10. M. Rother, R. Harris, Tworzenie ciaglego przepływu (Wrocławskie Centrum Transferu Technologii Politechniki Wrocławskiej, Wrocław, 2001)

11. M. Rother, J. Shook, Naucz się widzieć. Eliminacja marnotrawstwa przez Mapowanie Strumienia Wartości (Wrocławskie Centrum Transferu Technologii Politechniki Wrocławskiej, Wrocław, 2002)

12. S. Wojciechowski, Int. J. Mach. Tool. Manu., 89, 110-123 (2015)

13. S. Wojciechowski, P. Twardowski, M. Pelic, Procedia CIRP, 14, 113-118 (2014)

14. S. Wojciechowski, R.W. Maruda, P. Nieslony, G.M. Krolczyk, Int. J. Mech. Sci., 119, 360-369 (2016)

15. T. Kafel, M. Walczak, Koncepcje zarzadzania systemami wytwórczymi (ed.: M. Fertsch, S. Trzcieliński, Wydawnictwo Politechniki Poznańskiej, Poznań, 2005) 